\title{
Quantitative Acoustic Emission Fatigue Crack Characterization in Structural Steel and Weld
}

\author{
Adutwum Marfo, Ying Luo, and Chen Zhong-an \\ Faculty of Civil Engineering and Mechanics, Jiangsu University, Zhenjiang 212013, China \\ Correspondence should be addressed to Chen Zhong-an; chenzhan@ujs.edu.cn
}

Received 24 December 2012; Revised 25 March 2013; Accepted 8 April 2013

Academic Editor: Ghassan Chehab

Copyright (C) 2013 Adutwum Marfo et al. This is an open access article distributed under the Creative Commons Attribution License, which permits unrestricted use, distribution, and reproduction in any medium, provided the original work is properly cited.

\begin{abstract}
The fatigue crack growth characteristics of structural steel and weld connections are analyzed using quantitative acoustic emission (AE) technique. This was experimentally investigated by three-point bending testing of specimens under low cycle constant amplitude loading using the wavelet packet analysis. The crack growth sequence, that is, initiation, crack propagation, and fracture, is extracted from their corresponding frequency feature bands, respectively. The results obtained proved to be superior to qualitative $\mathrm{AE}$ analysis and the traditional linear elastic fracture mechanics for fatigue crack characterization in structural steel and welds.
\end{abstract}

\section{Introduction}

Paris and Erdogan [1] demonstrated that linear elastic fracture mechanics (LEFM) is a useful tool for characterizing crack growth by fatigue. Since that time, application of fracture mechanics to fatigue problems has become a fair routine. Acoustic emission technology is the most appropriate nondestructive testing (NDT) method for studying fatigue crack growth in civil engineering structure because it can monitor its health in real time [2]. Effective crack detection may lead to an early warning. The AE technique can be used to continuously detect slight deformation and damage in the interior of materials. In other words, sampling AE signals and analyzing their characteristics may contribute to the understanding of the real-time failure behavior of materials [3].

The AE parametric analyses have been commonly employed during fatigue crack growth characterization. Ohtsu and Tomoda [4] reported that the AE waveform shape depends on the cracking mode, enabling the classification of cracks in different materials. Shear cracks generally follow tensile as the material approaches to final failure. Yoneda and $\mathrm{Ye}$ [5] report that failure phenomena in metals can be interpreted by evaluating the amplitude distribution, $\mathrm{AE}$ event count, and total AE energy. Aggelis et al. [6] discuss the application of other AE parameters, such as rise angle (RA) value, rise time (RT), AE hit rate, and duration damage characterization of metal. They realized that as the duration and RT increase, there is a shift of cracking mode from tensile to shear. Boinet et al. [7] correlated the AE parameters like rise time and duration with corrosive processes in aluminium.

A good correlation between AE parameters and fracture mechanics principles during fatigue has been reported by $[8,9]$. Grosse et al. [10] reported the pros and cons of the parametric AE analysis. They postulated that in practical applications it can be difficult to discriminate an $\mathrm{AE}$ signal from noise after the signal has been reduced to a few parameters.

Quantitative techniques that deal with the study of $\mathrm{AE}$ signal waveform have been applied in various engineering fields for damage evaluation. The fast Fourier transform (FFT) has been used to decompose a time-domain sequence in terms of a set of basic functions. A major problem in using the FFT results from the fact that the transform is the result of integration in the continuous time domain over the entire signal length [11-13]. This problem led to the evolution of the time-frequency data processing methods, such as the short time Fourier transform (STFT). Neild et al. [14] provided a thorough review of various time-frequency techniques for structural vibration analysis. The wavelet transform which is the main interest of this paper has been successfully combined with AE signal parameter for analysis of real-time failure process, such as differentiation of crack types, quantification of damage, and identification of $\mathrm{AE}$ 
source locations [15-17]. This paper discusses the fatigue crack growth characterization in structural steel and weld using quantitative methods. The frequency feature bands corresponding to crack growth sequence, that is, initiation, crack propagation, and fracture, are extracted and compared with qualitative AE analysis and LEFM.

\section{Wavelet Packet Theory}

Wavelet transform, a contemporary technique for data and signal analysis, has already found its distinguished place in nondestructive testing. Wavelets are mathematical functions that cut up data into different frequency components and then study each component with a resolution matched to its scale. Several types of wavelets which could be successfully applied to AE analysis are Shannon wavelets, Haar wavelets, Daubechies wavelets, Meyer wavelets, Gaussian wavelets, Mexican hat wavelets, Morlet wavelets, and complex frequency B-spline wavelets.

The continuous wavelet transform of an arbitrary function $f(t)$ is defined as

$$
\begin{aligned}
W T_{x}(a, b) & =\frac{1}{\sqrt{|a|}} \int_{-\infty}^{\infty} x(t) \psi^{*}\left(\frac{t-b}{a}\right) d t \\
& =\left\langle x(t), \psi_{a, b}(t)\right\rangle,
\end{aligned}
$$

where

$$
\psi_{a, b}=\frac{1}{\sqrt{|a|}} \psi\left(\frac{t-b}{a}\right) \quad a, b \in R, a \neq 0 .
$$

The parameters " $a$ " and " $b$ " stand for scale and shift of the basic wavelet. For each scale " $a$ " and position " $b$ " the timedomain signal is multiplied by shifted and scaled versions of the wavelet function.

The discrete wavelet transform (DWT) of a discrete time sequence $x(n)$ is given as

$$
C_{j, k}=2^{(-j / 2)} \sum_{n} x(n) \psi\left(2^{-j} n-k\right),
$$

where $\psi(n)$ is the wavelet function and $2^{(-j / 2)} \psi\left(2^{-j} n-k\right)$ are scaled and shifted versions of $\psi(n)$ based on the values of scaling coefficient " $j$," and shifting coefficient " $k$ " wavelet packets transform (WPT) is a generalization of wavelet analysis offering a richer decomposition procedure. WPT can be used to decompose signals into different components in different time windows and frequency bands which can be considered as features of the original signals. Wavelet packets decompose the low frequency component as well as the high frequency component in every subband. The Gabor function is used as the analyzing wavelet because it provides a small window in the time as well as in the frequency domain.

Consider

$$
\Psi_{\mathrm{GABOR}}(t)=\frac{1}{\sqrt[4]{\pi}} \sqrt{\frac{\omega_{o}}{\gamma}} \exp \left[-\frac{\left(\omega_{o} / \gamma\right)^{2} t^{2}}{2}+i \omega_{o} t\right] .
$$

TABLE 1: Mechanical property of $16 \mathrm{Mn}$ steel and weld.

\begin{tabular}{lcccc}
\hline & $\sigma_{b}(\mathrm{MPa})$ & $\sigma_{s}(\mathrm{MPa})$ & $\delta(\%)$ & $E(\mathrm{MPa})$ \\
\hline Base metal & 360 & 560 & 37 & 206000 \\
Weld & 294 & 441 & 31 & 206000 \\
\hline
\end{tabular}

$\sigma_{b}$ : yielding stress, $\sigma_{s}$ : ultimate tensile stress, $\delta$ : percentage of elongation, $E$ : Young's modulus.

TABLE 2: Chemical properties of $16 \mathrm{Mn}$ steels.

\begin{tabular}{cccccc}
\hline $\mathrm{C}$ & $\mathrm{Mn}$ & $\mathrm{Si}$ & $\mathrm{S}$ & $\mathrm{P}$ & $\mathrm{Ca}$ \\
\hline 0.16 & 1.42 & 0.31 & 0.033 & 0.022 & 0.10 \\
\hline
\end{tabular}

In the frequency domain, the Gabor function is represented as

$$
\Psi_{\mathrm{GABOR}}=\frac{2 \pi}{\sqrt[4]{\pi}} \sqrt{\frac{\gamma}{\omega_{o}}} \exp \left[-\frac{\left(\gamma / \omega_{o}\right)^{2}}{2}\left(\omega-\omega_{o}\right)^{2}\right] .
$$

\section{Experimental Details}

3.1. Specimens Design. Received hot-rolled $16 \mathrm{Mn}$ steel was supplied in the standard thermomechanical heat treatment condition in the form of $16 \mathrm{~mm}$ thickness plates. The standard three-point bending (SENB) specimens were designed from the steel and the butt welded connection, as a representative part of a steel bridge in accordance with ASTM E647 standards. The mechanical properties and chemical composition of the specimens used are shown in Tables 1 and 2, respectively. The specimens were notched using electrical discharge machining (EDM) to an initial crack length of $18 \mathrm{~mm}$. The specimen was fatigue precracked using the MTS machine at a frequency of $10 \mathrm{~Hz}$ of length $0.5 \mathrm{~mm}$. The specimens' surfaces were mechanically polished by grinding and buffing to permit observations of the crack path. The detailed geometry of the specimen is illustrated in Figure 1.

3.2. Test Instrument and Procedure. A servohydraulic testing machine with a maximum load capacity of $250 \mathrm{kN}$ was used for the fatigue tests at an ambient temperature of $300 \mathrm{~K}$ (Figure 2). The specimens were tested under sinusoidal cyclic loading at a frequency of $7.5 \mathrm{~Hz}$. The specimens were tested with different peak loads $(16 \mathrm{kN}$ and $10 \mathrm{kN})$ at a load R-ratios of 0.1 . At least three specimens were tested under each condition in other to ensure regularity in the experiment. A SWAES full-waveform acoustic emission detector was used to record the $\mathrm{AE}$ signals generated during the fatigue tests.

The AE signals were detected by using 2 broadband piezoelectric sensors with frequency range of $10 \mathrm{kHz}$ to $2 \mathrm{MHz}$. Vaseline was used at the interface between the sensors and the specimen surface to obtain proper signals. A preamplifier of 


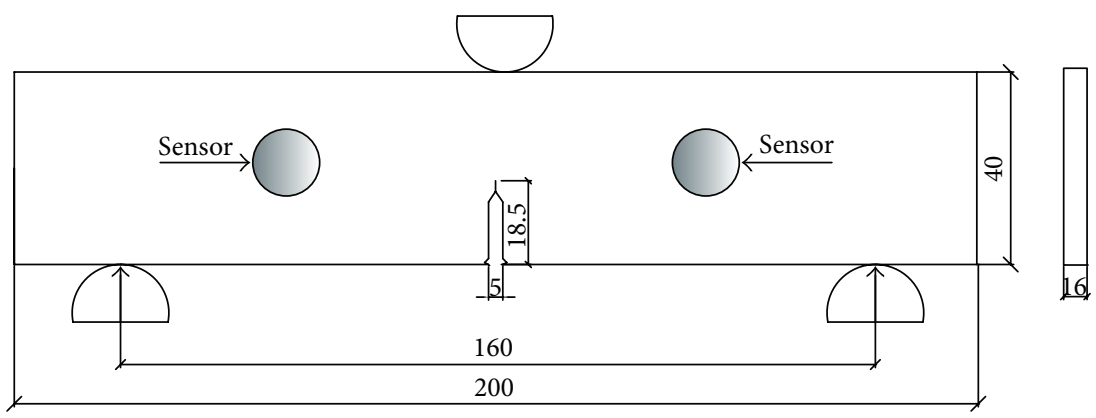

FIGURE 1: Specimen geometry.

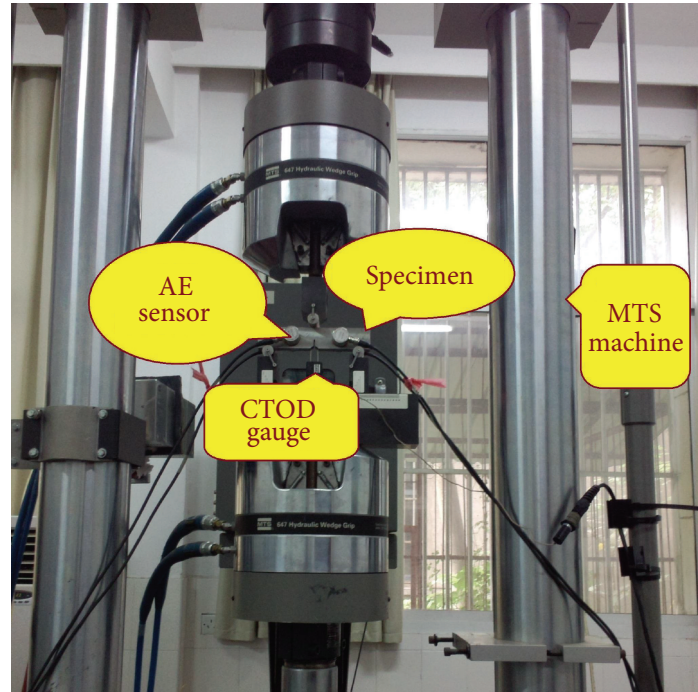

Figure 2: Experimental setup.

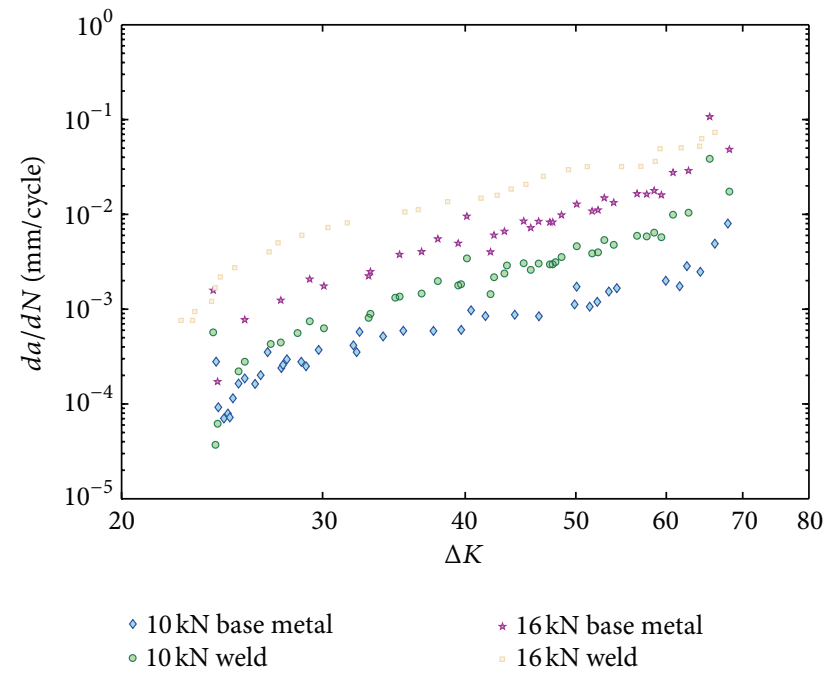

FIGURE 3: Relationships between crack growth rates and stress intensity factor range.

$40 \mathrm{db}$ gain was used to capture the AE signals. The crack-tip opening-displacement gauge (CTOD) was used to monitor

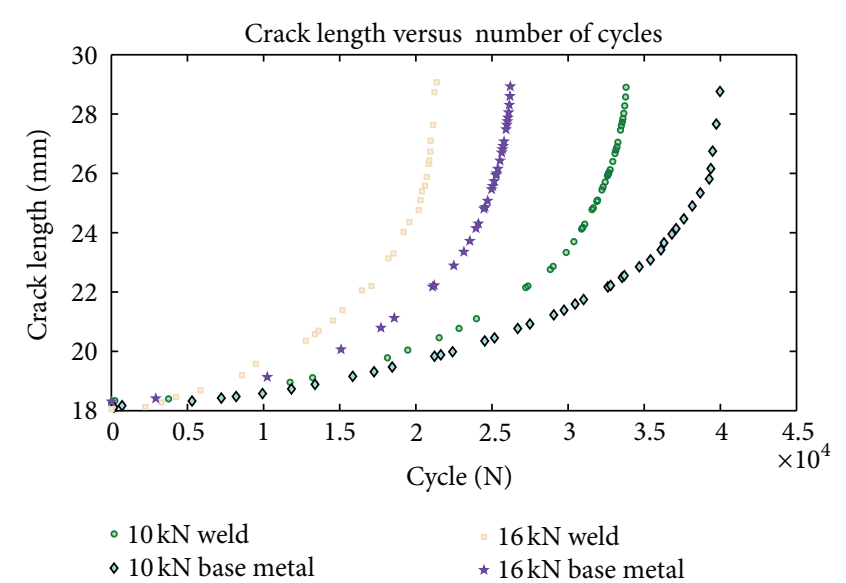

FIGURE 4: Relationships between crack length and number of cycles.

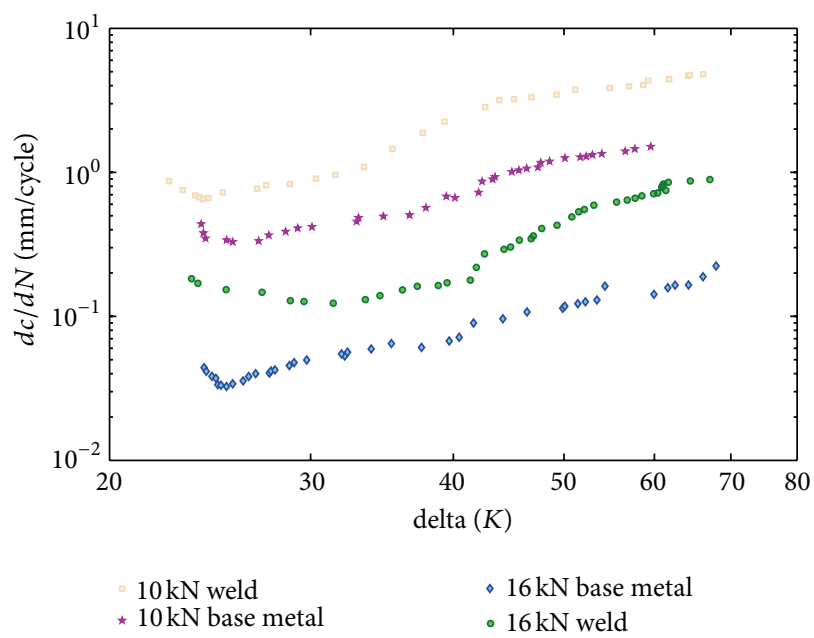

FIGURE 5: Relationship between cumulative count rate and stress intensity factor range.

the fatigue crack growth in the structure. The crack length at any given cycle was arithmetically computed using

$$
\begin{aligned}
\frac{a}{w}= & 0.999748-3.9504 U_{v}+2.981 U_{V}^{2}-3.21408 U_{V}^{3} \\
& +51.51564 U_{V}^{4}-113.031 U_{V}^{5},
\end{aligned}
$$




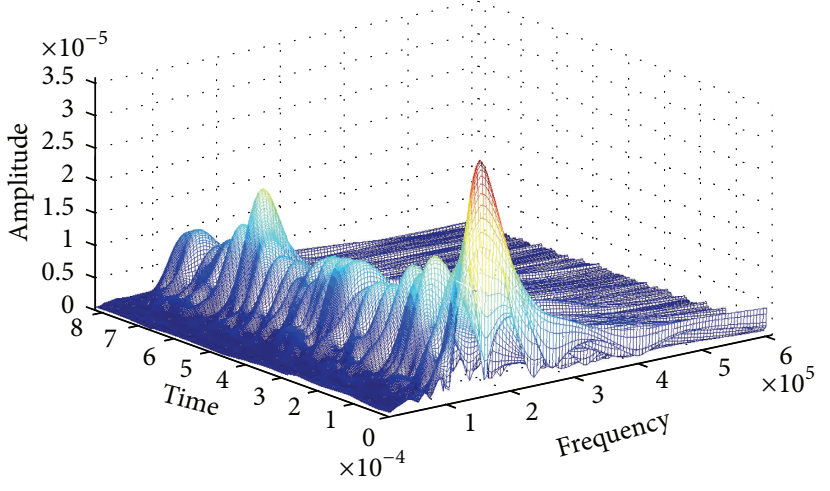

(a)

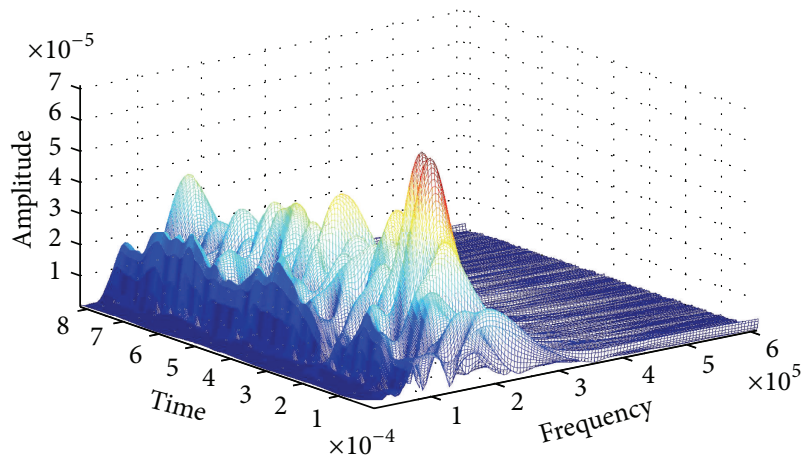

(b)

FIgURE 6: Fatigue crack initiation (a) base metal and (b) welded specimen.

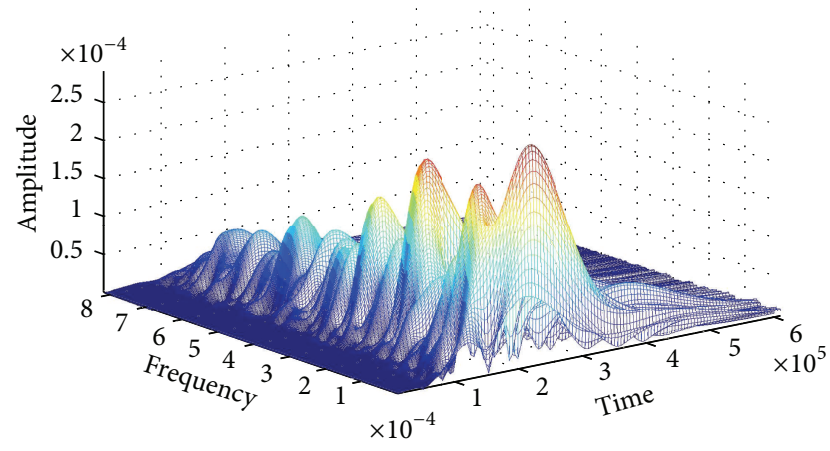

(a)

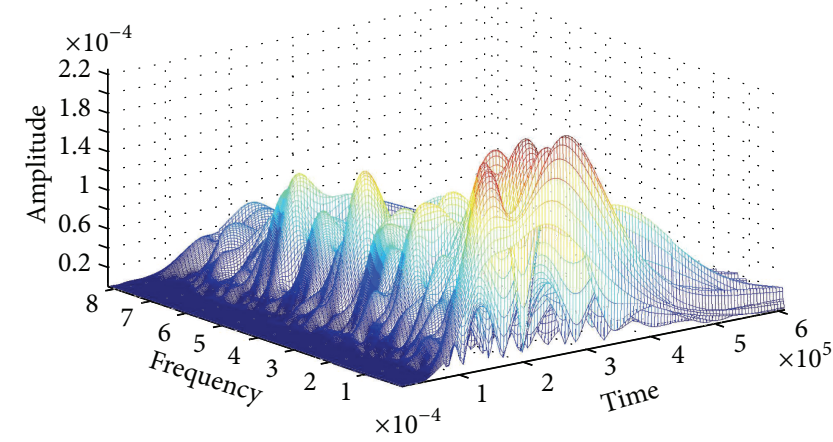

(b)

FIGURE 7: Fatigue crack propagation (a) base metal and (b) welded specimen.

where $U_{v}=1 / \sqrt{\left(4 z_{v} w / s\right)+1}, Z_{v}=B E V / P, V=$ crack-mouth-opening displacement, $a=$ crack length, $W=$ specimen width, $B=$ specimen thickness, $S=$ span, and $E=$ modulus of elasticity.

\section{Results and Discussions}

4.1. Linear Elastic Fracture Mechanics. Paris and Erdogan [1] discovered the power-law relationship for the fatigue crack growth and proposed an exponent of 4 for the constant $m$ after series of experiments. Figures 3 and 4 show the relationship between $d$ the fatigue crack growth rates $(d a / d N)$ and stress intensity factor ranges $(\Delta K)$ and crack length and number of cycles under different load ratios, respectively.

In nearly the whole fatigue lives, they obeyed the Paris law (7) for the steel and welds

$$
\frac{d a}{d N}=C \Delta K^{m}, \quad \log \left(\frac{d a}{d N}=\log C+m \log \Delta K\right),
$$

where $a$ is a representative crack length, $n$ is the number of fatigue cycles, $\Delta K$ is the applied stress intensity factor range, and $C$ and $m$ are assumed to be constants for a particular material. However, the crack growth rates were increased in the weld relative to in the base metal, suggesting that the cracks propagated more rapidly in the weld due to the changes in the microstructure. We realized from the diagram that peak load was less significant on the crack propagation rate.

\subsection{Acoustic Emission during Fatigue Crack Propagation.} The fatigue crack growth characteristics can be analyzed by studying the parameters of the AE signals so generated. Figure 5 shows the relationships between the cumulative $\mathrm{AE}$ counts rates $(d C / d N)$ and stress intensity factor ranges $\Delta K$ for the welded specimens under different peak loads. The $\mathrm{AE}$ counts rates increased in a linear relationship with the increase in $\Delta K$ on the log-log axes, which is well consistent with (7). Compared to the results from LEFM, the peak load had influence on $d C / d N$ on the welded specimen. Moreover, higher AE counts rates were also observed in the welded specimens than in the base metal specimens. In addition, the slopes of the lines for the welded specimens were somehow higher than the base metal specimens, also suggesting that the weld generated more AE signals during fatigue crack propagation.

4.3. Wavelet Packet Analysis. The characteristics of fatigue crack propagation during the three-point bending testing of the steel beam and weld connection are classified under 


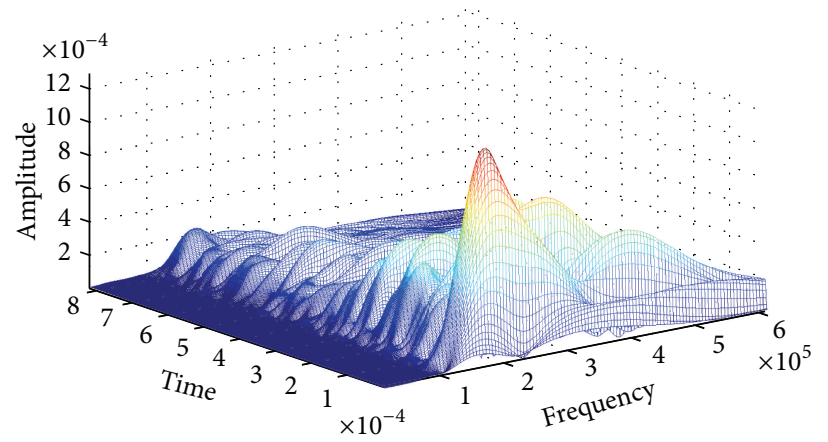

(a)

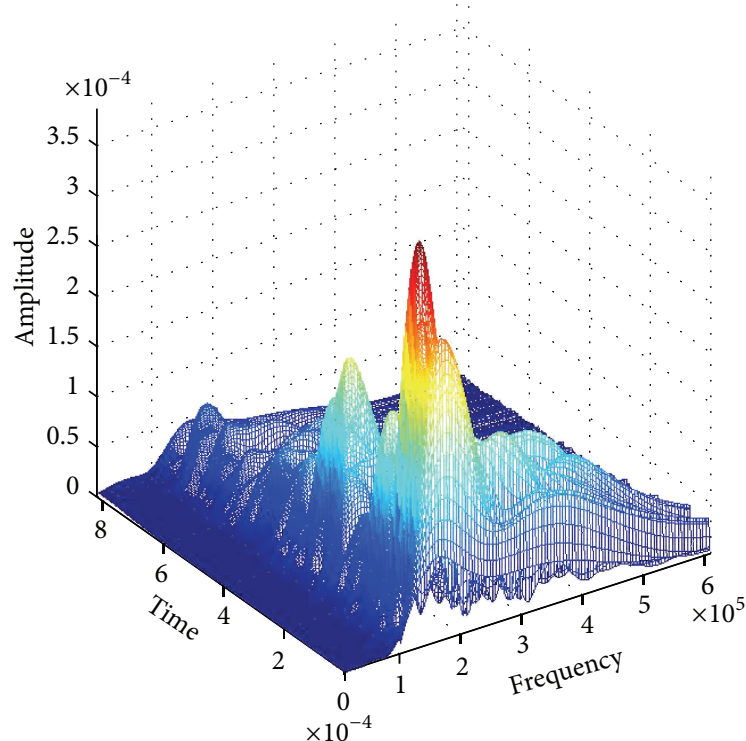

(b)

Figure 8: Fracture (a) base metal and (b) welded specimen.

3 stages: crack initiation, crack propagation, and failure at various peak loads corresponding to regions I, II, and III, respectively.

Figures 6(a) and 6(b) show the AE wave in region 1 which corresponds to fatigue source initiation for both weld metal and base metal, respectively. The waveform is low amplitude, wide pulse with a narrow frequency scale, mostly located at $80 \mathrm{kHz}$ to $180 \mathrm{kHz}$. At this stage, the AE signals are generated by the formation of crack source and plastic deformation on the tip of the notch which generate intense AE events. Higher amplitudes are recorded for the weld than the base metal due to the release of residual stresses. Figures 7(a) and 7(b) show the $\mathrm{AE}$ in region 2 corresponding to fatigue crack propagation. The waveform at this stage as compared to the fatigue source has high amplitude, narrow pulse, with a wide energy scale, and a main frequency scale of $250 \mathrm{kHz}$ to $350 \mathrm{kHz}$ for the base metal and $250 \mathrm{kHz}$ to $450 \mathrm{kHz}$ for the welded specimen.

Figures 8(a) and 8(b) show the AE waveform at the rapid crack propagation stage; the energy of the AE signal increased until the specimen completely failed, and the AE waveform amplitude is higher than those of the earlier stages. The waveform characteristic shows that this type of AE signal is a burst signal. The fracture waveform is a high amplitude narrow pulse, with a wide energy scale, and a main frequency scale of $300 \mathrm{kHz}$ to $400 \mathrm{kHz}$ for the base metal and between $300 \mathrm{kHz}$ and $600 \mathrm{kHz}$ for the welded specimen.

\section{Conclusion}

From the above discussions, it is evident that fatigue crack growth rates for the welded specimen are higher than the base metal; this was enhanced by the presence of inclusions and heterogeneous microstructure of the welds. The effect of peak load on fatigue characterization was found to be insignificant. Furthermore, the quantitative technique of the wavelet transform provided clear results for crack propagation characterization in both the steel and welded specimen.

\section{References}

[1] P. C. Paris and F. Erdogan, "Critical analysis of crack propagation Laws," Journal of Basic Engineering, vol. 85, pp. 528-534, 1960.

[2] T. M. Roberts and M. Talebzadeh, "Fatigue life prediction based on crack propagation and acoustic emission count rates," Journal of Constructional Steel Research, vol. 59, no. 6, pp. 679694, 2003.

[3] L. Yang, Y. C. Zhou, W. G. Mao, and C. Lu, "Real-time acoustic emission testing based on wavelet transform for the failure process of thermal barrier coatings," Applied Physics Letters, vol. 93, no. 23, Article ID 231906, 2008.

[4] M. Ohtsu and Y. Tomoda, "Phenomenological model of corrosion process in reinforced concrete identified by acoustic emission," ACI Materials Journal, vol. 105, no. 2, pp. 194-199, 2008.

[5] K. Yoneda and J. Ye, "Crack propagation and acoustic emission behavior of silver-added Dy123 bulk superconductor," Physica C, vol. 445-448, no. 1-2, pp. 371-374, 2006.

[6] D. G. Aggelis, E. Z. Kordatos, and T. E. Matikas, "Acoustic emission for fatigue damage characterization in metal plates," Mechanics Research Communications, vol. 38, no. 2, pp. 106-110, 2011.

[7] M. Boinet, J. Bernard, M. Chatenet, F. Dalard, and S. Maximovitch, "Understanding aluminum behaviour in aqueous alkaline solution using coupled techniques. Part II: acoustic emission study," Electrochimica Acta, vol. 55, no. 10, pp. 3454-3463, 2010.

[8] P. Johan Singh, C. K. Mukhopadhyay, T. Jayakumar, S. L. Mannan, and B. Raj, "Understanding fatigue crack propagation in AISI $316(\mathrm{~N})$ weld using Elber's crack closure concept: 
experimental results from GCMOD and acoustic emission techniques," International Journal of Fatigue, vol. 29, no. 12, pp. 2170-2179, 2007.

[9] K. Bruzelius and D. Mba, "An initial investigation on the potential applicability of Acoustic Emission to rail track fault detection," NDT and E International, vol. 37, no. 7, pp. 507-516, 2004.

[10] C. U. Grosse, H. Reinhardt, and T. Dahm, "Localization and classification of fracture types in concrete with quantitative acoustic emission measurement techniques," NDT and E International, vol. 30, no. 4, pp. 223-230, 1997.

[11] S. Park, N. Stubbs, and R. W. Bolton, "Damage detection on a steel frame using simulated modal data," in Proceedings of the 16th International Modal Analysis Conference (IMAC '98), pp. 616-622, Santa Barbara, Calif, USA, February 1998.

[12] W. X. Ren and G. de Roeck, "Structural damage identification using modal data. I: simulation verification," Journal of Structural Engineering, vol. 128, no. 1, pp. 87-95, 2002.

[13] S. W. Doebling, C. R. Farrar, and M. B. Prime, "A summary review of vibration-based damage identification methods," Shock and Vibration Digest, vol. 30, no. 2, pp. 91-105, 1998.

[14] S. A. Neild, P. D. McFadden, and M. S. Williams, "A review of time-frequency methods for structural vibration analysis," Engineering Structures, vol. 25, no. 6, pp. 713-728, 2003.

[15] H. Kim and H. Melhem, "Damage detection of structures by wavelet analysis," Engineering Structures, vol. 26, no. 3, pp. 347362, 2004.

[16] M. A. Hamstad, A. O'gallagher, and J. Gary, "A wavelet transform applied to acoustic emission signals: part 1: source identification," Journal of Acoustic Emission, vol. 20, pp. 39-61, 2002.

[17] R. Khamedi, A. Fallahi, and A. R. Oskouei, "Effect of martensite phase volume fraction on acoustic emission signals using wavelet packet analysis during tensile loading of dual phase steels," Materials and Design, vol. 31, no. 6, pp. 2752-2759, 2010. 

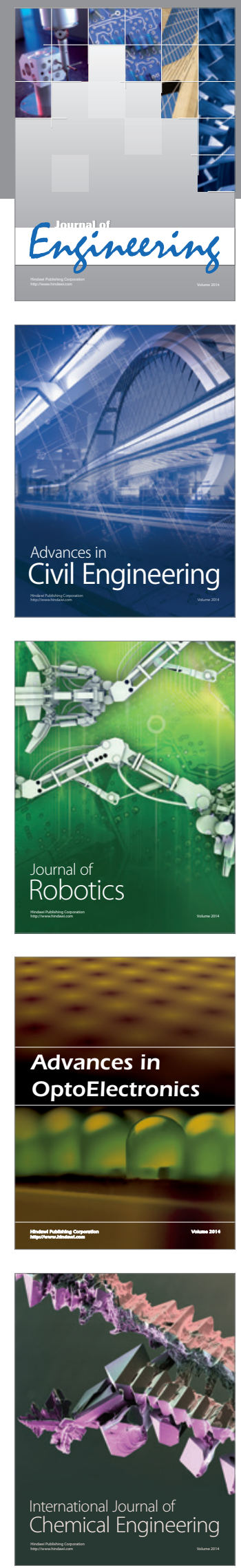

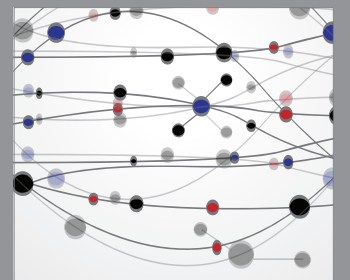

The Scientific World Journal
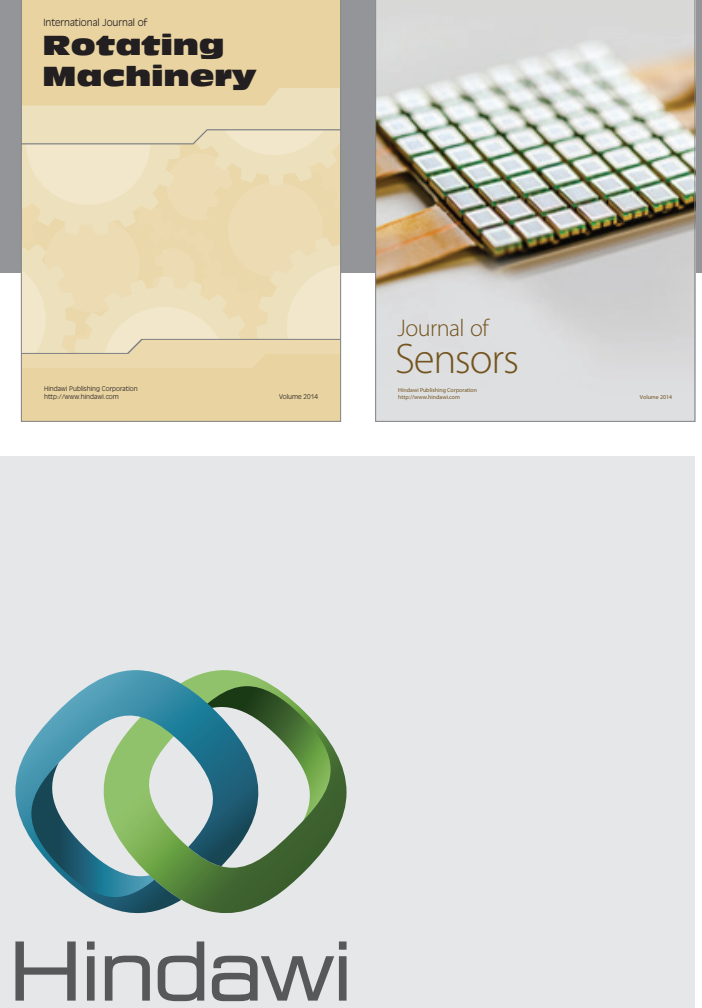

Submit your manuscripts at http://www.hindawi.com
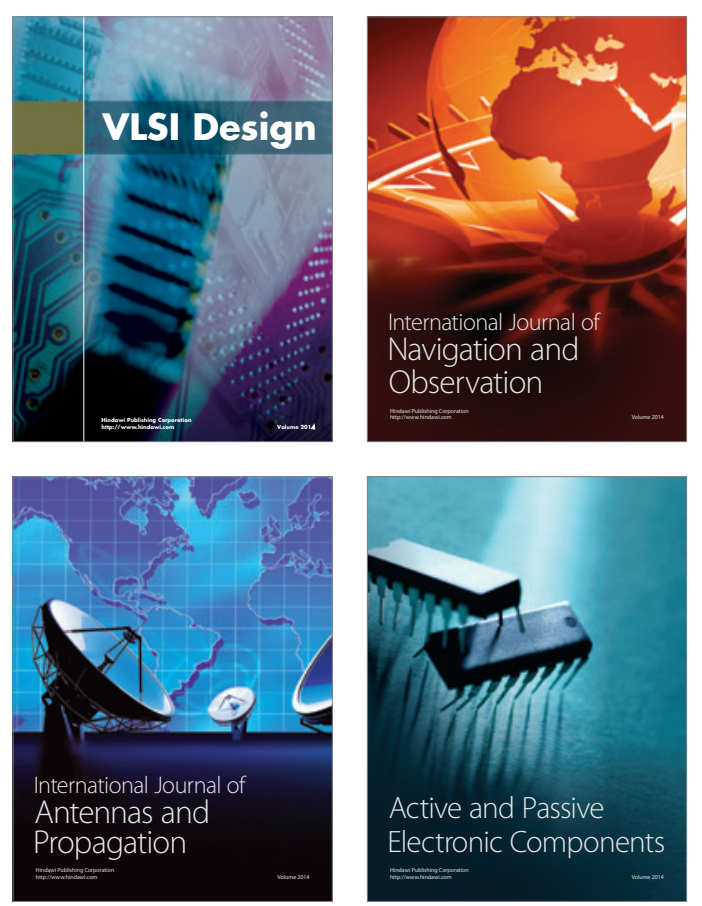
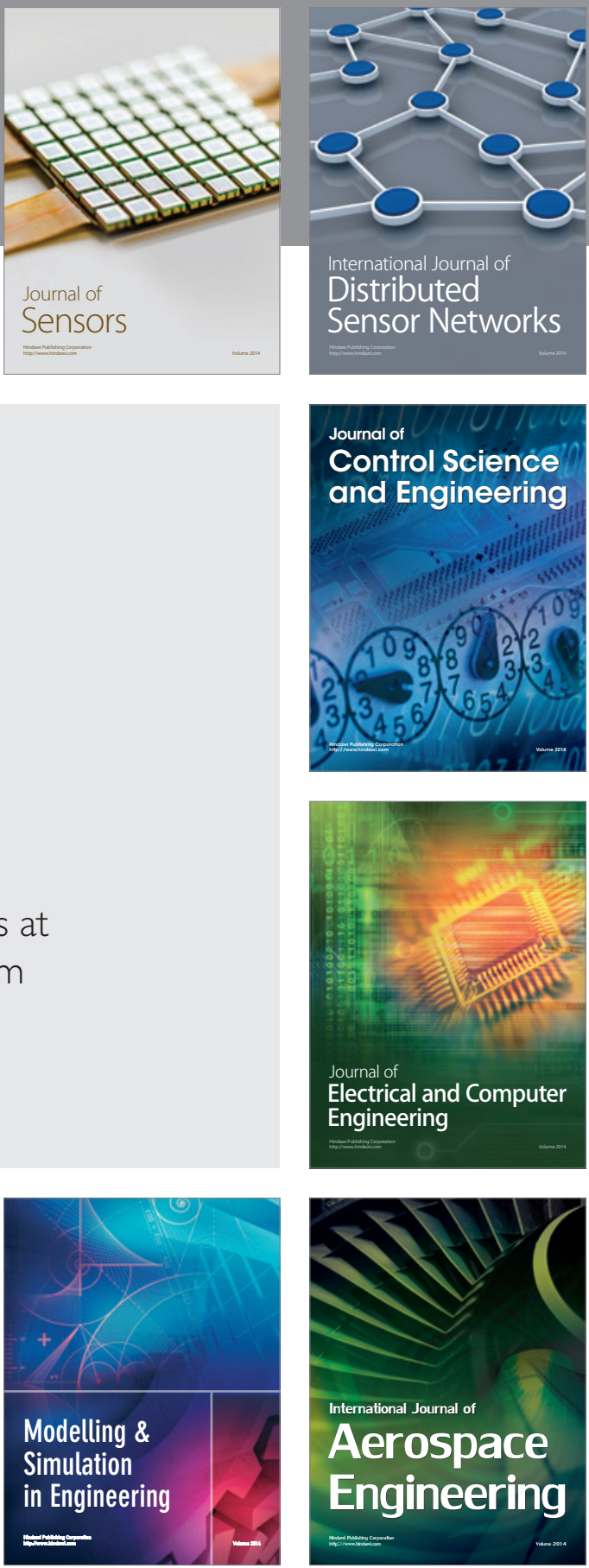

Journal of

Control Science

and Engineering
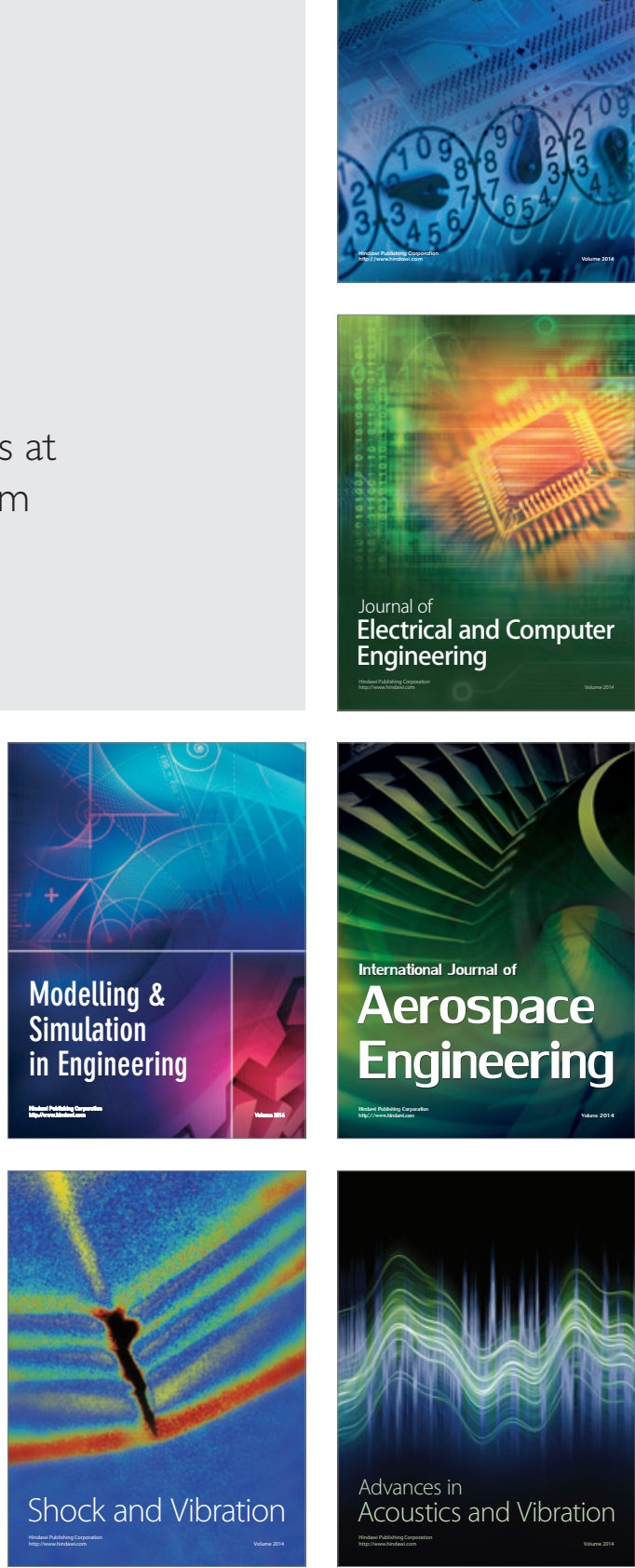